\title{
Una perspectiva del mundo del idish y el asociacionismo cultural judío (Tucumán, 1925-1932) Una perspectiva del mundo del idish y el asociacionismo cultural judío
}

An outlook on the Yiddish world and Jewish cultural associations (Tucumán, 1925-1932)

\author{
Vanesa Teitelbaum \\ vteitel@yahoo.com
}

\section{Resumen}

A partir de la visita a Tucumán que realizó en 1932 el editor y escritor de origen ruso Zalmen Reisen (1887-1941), en su papel de delegado del Instituto Científico Judío de Vilna, el propósito de esta pesquisa es avanzar en un campo de estudios poco explorado, referido al universo del idish y la cultura en el asociacionismo judío tucumano de entreguerras. Sin el objetivo de agotar el tema, el artículo examina algunas prácticas de asociación, indaga actividades artísticas - culturales y concluye con una reflexión acerca de las características del asociacionismo judío tucumano entre finales de los años 1920 y comienzos de los `30.

Palabras claves: Instituto Científico Judío, asociaciones judías, manifestaciones culturales, presentaciones artísticas.

\begin{abstract}
As a result of a visit made to Tucumán by Russian-born editor and writer Zalmen Reisen (18871941 ) in 1932, as a delegate of Vilna's Yiddish Scientific Institute, the aim of the present work is to make headway in an almost unexplored field of study; that related to Yddish and culture within Tucumán's Jewish associations in the time between the two great wars. By no means wishing to be comprehensive, this article examines some associative practices, delves into artistic and cultural activities, and leads to some considerations regarding the characteristics of Tucumán's Jewish associations between the late 1920s an the beginning of the'30s.
\end{abstract}

Key words: Yddish Scientific Institute, Jewish associations, cultural manifestations, artistic performances.

\section{Introducción}

En general, los trabajos sobre inmigración judía en Tucumán se elaboraron desde el propio marco institucional de las asociaciones judías. Una muestra en ese sentido, fue el estudio redactado por Isidoro Blumenfeld (1971) con motivo de cumplirse en 1970 el 60 aniversario de la fundación de la Sociedad Unión Israelita Tucumana. Apoyándose sobre todo en la documentación de esta asociación medular del asociacionismo judío tucumano, fundada al despuntar la década de 1910, el autor reconstruyó la vida comunitaria judía en la provincia desde sus orígenes y hasta finales de los 
años 1960. En gran medida, es posible considerar su trabajo como una obra pionera que permitió detectar aspectos centrales del accionar judío en la provincia.

A partir de este estudio precursor, Elisa Cohen de Chervonagura (2010) profundizó después la historia de la Sociedad Unión Israelita en un libro que contó con el aporte de colaboradores provenientes de distintas disciplinas, incluyó entrevistas a miembros de la comunidad judía y se convirtió en una referencia insoslayable sobre el tema. ${ }^{1}$

Por su parte, María Esther Silberman de Cywiner (2006 y 2012) se abocó especialmente al análisis de la comunidad judía tucumana de origen sefaradí. Temáticas amplias y diversas, como la comida, las canciones y los usos del lenguaje, fueron abordados en sus trabajos que concedieron un lugar relevante a las entrevistas a inmigrantes y sus descendientes y recogieron además la colaboración de otros investigadores.

También recurrió a las entrevistas Denise León (2002), quien reconstruyó y analizó la vida de cinco mujeres, de origen judío ashkenazi y sefaradí. Además de estos estudios --elaborados varios de ellos desde la perspectiva de la literatura-- contamos con otros valiosos aportes, por ejemplo las contribuciones coordinadas por la arquitecta Diana Mizrahi, quien condujo un equipo de trabajo orientado al rescate de las voces de los abuelos inmigrantes, tal como se reflejó en el video "El Sentir de los pueblos". ${ }^{2}$

Apoyada en estos diversos análisis, recientemente inicié una línea de trabajo centrada en la inmigración judía en Tucumán de entreguerras, haciendo especial hincapié en los aspectos culturales y en el mundo del idish, temática prácticamente inexplorada por la historiografía para el espacio y el periodo elegido. ${ }^{3}$ ¿Cómo era la vida cultural judía en la época?, ¿qué lugar ocupó el idish en las expresiones artísticas, culturales y asociativas?, ¿cómo fueron las relaciones entre los miembros de la comunidad judía y otros sectores de la sociedad tucumana? y, ¿cuáles fueron los principios que rigieron el asociacionismo judío tucumano?, son algunas de las preguntas que motivaron esta investigación.

1 Recientemente, además, la autora ahondó en la vida de dos mujeres: una, prostituta y otra, una santa, en un novedoso trabajo pensado para reconstruir y comprender la historia de la comunidad judía tucumana, con sus heterogeneidades, tensiones y silencios. Al respecto, Elisa Cohen de Chervonagura, Eshet Jail, Un contrapunto entre dos mujeres judías, Tucumán, Universidad Nacional de Tucumán, 2015.

2 Es importante advertir que los trabajos mencionados no pretenden agotar la totalidad de la bibliografía disponible.

3 Sin el objetivo de ofrecer un listado completo, me sirvieron especialmente los estudios sobre esta temática para Buenos Aires, por ejemplo: Dujovne (2014), Chinski (2011) y Bargman (2011). Dos balances muy sugerentes sobre las contribuciones elaboradas en el contexto de la revitalización temática y de perspectivas de análisis que experimentan en la actualidad los estudios judíos en Argentina y Latinoamérica son los de Gleizer y Kahan (2017) y Kahan y Dujovne (2017). 
En ese contexto de preocupaciones, el trabajo se concentrará en algunas actividades de naturaleza cultural llevadas adelante por las asociaciones judías, especialmente aquellas de origen ashkenazi, durante el durante el periodo comprendido, aproximadamente, entre mediados de la década de 1920 y comienzos de los años $1930 .{ }^{4}$ En particular, examinaré la visita del escritor, editor y periodista de origen ruso Zalmen Reisen (1887-1941), quien en 1932 llegó a Tucumán como parte de una misión cultural en su papel de delegado del prestigioso Instituto Científico Judío (YIVO), creado en Vilna en 1925 y cuya sede en Buenos Aires se fundó en 1928 y es conocido actualmente con las siglas IWO. ${ }^{5}$

Sin el propósito de agotar el tema con estas páginas, pero sí mostrar aspectos novedosos, a partir del análisis de esta visita, aspecto prácticamente inexplorado por la bibliografía sobre la comunidad judía en Tucumán, reconstruiré después el mundo del asociacionismo judío local y mencionaré algunas expresiones culturales y artísticas significativas durante la época estudiada.

Para llevar adelante este trabajo, aprovecharé las herramientas de la historia social y con una metodología de corte cualitativo, analizaré principalmente la prensa, en especial las narraciones difundidas por uno de los diarios locales más importantes como fue El Orden. Esta información se completará y contrastará con otras fuentes, como los documentos difundidos por el YIVO y el IWO y escritos autobiográficos. ${ }^{6}$

Una de las hipótesis que subyace en este trabajo propone como hacia finales de los años 1920 y comienzos de los '30, en una escena signada por las repercusiones de la política nacional e internacional que dramáticamente viraban hacia la derecha, la vida cultural tucumana experimentó un gran desarrollo. Muestras de este crecimiento fueron los abundantes artículos de la prensa que sistemáticamente informaban acerca de estrenos cinematográficos, nuevas obras de teatro, conferencias y visitas de renombradas figuras que procedentes de otras ciudades argentinas o del extranjero recorrían la provincia como parte de sus giras científicas, culturales y artísticas. ${ }^{7}$

Fue en ese contexto de vitalidad cultural en el cual se desarrolló un rico movimiento asociativo judío y adquirió protagonismo el universo del idish y sus expresiones culturales en diversos ámbitos como la literatura, la poesía y el teatro. Sin embargo, la Segunda Guerra Mundial y el nazismo clausuraron el crecimiento de esta cultura característica de la vida judía europea, cuyas manifestaciones habían llegado a la Argentina mediante la inmigración.

4 En la época bajo estudio se contabilizaban en Tucumán 400 familias ashkenazitas (Blumenfeld, 1971).

5 El Instituto Científico Judío es conocido por su acrónimo en idish YIVO. Por su parte, la sede del Instituto establecida en Buenos Aires en 1928 es conocida como IWO.

6 Por ejemplo, Singerman (1981).

7 Un renglón especial lo ocupaban los eventos deportivos que alcanzaron un lugar destacado en las páginas de los principales diarios locales. 


\section{Un sabio judío en Tucumán: la visita de Zalmen Reisen en 1932}

En julio de 1932 el renombrado periodista ruso Zalmen Reisen estuvo en Tucumán como parte de una misión cultural en Argentina destinada a recaudar fondos para el Instituto Científico Judío (YIVO), mencionado por El Orden como "Jiwo Bleter", cuya sede principal se encontraba en la ciudad lituana Vilna. Procedente de Córdoba, Reisen fue recibido en la estación del ferrocarril por los integrantes del sub-comité local de la sección argentina del Instituto Científico Judío, por los representantes de las instituciones israelitas locales y por destacados miembros de esa colectividad. De acuerdo a los artículos publicados por El Orden, sabemos que al poco tiempo de llegar, Reisen visitó las oficinas del diario, acompañado por los principales dirigentes comunitarios. El vicepresidente de la Sociedad Unión Israelita, el Sr. Isaac Aiziczon, el presidente de la Sociedad Unión Israelita Residentes de Polonia, el Sr. Herman Gura, junto con el Sr. Santiago Kohon, prosecretario de la misma entidad, David Lis, presidente del Centro Cultural Sionista Tucumano, Samuel Puhfkin y Salomon Freiberg formaron parte de la comitiva. ${ }^{8}$

Como la visita de Reisen a Tucumán se enmarcaba dentro de su gira de estudio por Argentina, en representación del YIVO, no fue extraño su interés por averiguar cuál era la situación de los israelitas en Sud América. En esa dirección, aseguraba estar admirado de la buena posición en que se encontraban y de la obra progresista que realizaban en el país los judíos. ${ }^{9}$ En esa dirección y a riesgo de caer en un par de digresiones, no resulta descabellado vincular los elogios del viajero con los habituales comentarios positivos que realizaban los visitantes extranjeros cuando conocían a los miembros de las colectividades de inmigrantes de sus mismos orígenes. Tal fue el caso, por ejemplo, de lo ocurrido varios años atrás, cuando visitó la provincia el delegado de la Alianza Francesa en América Latina y del Ministerio de Comercio e Industrias de Francia, el ingeniero Luis Albertini. Así, al conocer a la comunidad inmigrante francesa reunida en el viceconsulado de Francia en la provincia, sus palabras destacaron la cultura, laboriosidad y espíritu de progreso de sus miembros, quienes además sentían un noble amor por Argentina. ${ }^{10}$

En su carácter de delegado del Instituto Científico de Vilna, Reisen explicaba que la labor de dicho organismo consistía en la coordinación de trabajos de sus asociados sobre filología, estadística, psicología, bibliografía, pedagogía, etnografía, folklore y teatro judío. También comentaba, al referirse a la labor del Instituto Científico, que se trataba de una organización única en su género, la cual en poco tiempo había crecido hasta convertirse en una organización mundial con secciones en una veintena de países y con colaboradores y corresponsales en cada rincón de la tierra.

La descripción que realizaba Reisen sobre el Instituto era correcta, ya que, ciertamente éste contaba con más de 20 secciones distribuidas en todo el mundo, y su labor se centraba en la coordinación de trabajos de sus asociados sobre filología, estadística, psicología, bibliografía, pedagogía, etnografía, folklore y teatro judío. Al respecto, interesa agregar que el comité directivo del Instituto estaba

8 El Orden, 18/7/1932.

9 El Orden, 17/7/1932 y 18/7/1932.

10 El Orden, 4/9/1912.

Cuadernos Judaicos ISSN: 07188749

N 36 -Diciembre 2019

176 
integrado por renombradas personalidades, de la talla de Albert Einstein, Sigmund Freud y Simón Dubnow, renombrado historiador.

\section{Su trayectoria como escritor y editor}

Respecto a la trayectoria de Reisen es importante apuntar que él fue un intelectual que construyó una reconocida carrera en el campo de la cultura y, especialmente, en el terreno de la lingüística y la literatura. En esos parámetros podemos inscribir el perfil elaborado por El Orden que rescataba sus obras Gramática del Idish, Enciclopedia de la literatura, prensa y filología judía e Historia de la literatura judía desde Mendelson hasta Mendele. Además, el diario mencionaba entre sus actividades la presidencia del P.E.N Club Israelita de Vilna, asociación de poetas, ensayistas y novelistas, y la dirección del diario Vilner Tog de la misma ciudad. ${ }^{11}$

A partir de los datos obtenidos en otras fuentes, es posible completar la información sobre la trayectoria de Reisen. Nacido en Koidanov, en la gobernación de Minsk (Rusia) --actualmente la zona pertenece a Bielorrusia-- en una familia cuyos miembros se dedicaron también al terreno de la cultura y las letras, comenzó su carrera ayudando a su hermano Avrom en libros de textos para aprender el idioma y la gramática idish. ${ }^{12}$ En ese contexto, podemos situar el primer volumen de su Gramatik fun der yidisher shprakn (Gramática del yidish Language, 1920) que surgió de la primera edición de su Yiddishe gramatik (Yiddish Grammar, 1908). Aunque el segundo volumen de esta obra no llegó a publicarse, algunas secciones de este trabajo se conocieron en revistas. Además, Reisen tradujo obras al idish, entre las cuales se destacaron las de Dostoevsky y Maupassant.

El aporte principal de Reisen a la cultura literaria idish fue el Diccionario biográfico de literatura y prensa idish, de 1914. En esa obra, se plasmó su esfuerzo por reconstruir y sistematizar materiales no recopilados previamente sobre escritores idish. Además, incluyó una lista de publicaciones periódicas idish. Posteriormente este trabajo se amplió y dio lugar al Diccionario biográfico de literatura yiddish, prensa y filología, 4 volúmenes, 1926-1929, obra que sigue siendo "el libro de referencia fundamental en el campo y la fuente principal del Diccionario biográfico de nueva literatura yiddish, 8 volúmenes, 1956-1981". ${ }^{13}$

El recorrido profesional de Reisen incluyó varios momentos claves. 1915, cuando se estableció en Vilna y se dedicó al periodismo, trabajando para diarios como Letse nayes, al inicio de su carrera, concretamente desde 1916 a 1919, y Vilner Tog, a partir de 1919. Esta segunda publicación que editó desde 1919 a 1939 conoció distintos nombres, como Undzer tog y otras denominaciones que fueron cambiando a su vez debido a la censura polaca. En esa dirección, es importante apuntar que "radical en su naturaleza, el periódico apoyó a escritores yiddish y sirvió como una plataforma para

11 El Orden, 18/7/1932.

12 También El Orden hacía mención a este aspecto, al indicar que Reisen integraba una familia de literatos: su hermana, Sara Reisen era una notable escritora judía y su hermano, Abraham Reisen, era un poeta de gran reconocimiento.

13 Novershtern, 2010 y https://en.wikipendia.org/wiki/Zalman_Reisen, última edición el 24/05/2018. 
la intelectualidad yiddish de Vilna". En esa ciudad, conocida como la "Jerusalén del Este por su rica vida cultural judía, Reisen participó activamente de la vida comunitaria y cultural e intervino en varias de sus múltiples organizaciones, como por ejemplo la Asociación de Escritores y Periodistas Judíos y el Club Yiddish PEN. Su interés por la vida judía en Vilna se plasmó, por ejemplo, en una obra monumental: Pinkes far der geshikte, diversión Vilne in di yorn diversión milkhome un okupatsye (Annales de la historia de Vilna en los años de la guerra y ocupación, 1922), que puede ser considerada como un modelo de historiografía local sobre el pasado reciente.

Respecto a su investigación literaria idish debemos resaltar que ésta se centró en la Haskalah y en las obras populares del siglo XIX. En esos parámetros podemos inscribir sus trabajos Fun Mendelson biz Mendele (De Mendelssohn a Mendele, 1923), que acercó al lector a una extensa selección de obras de escritores yiddish de finales del siglo XVIII y XIX. Asimismo, fue el editor de la revista Yidishe filologye (1924-1926) y de Fislologishe shriftn (3 volúmenes, 1926-1929) y miembro del Consejo Editorial y, posteriormente, editor de Yivo Bleter (1931-1939), en el que publicó investigaciones y críticas.

Fue en esa época, también, en la cual se enmarcaron sus viajes a Estados Unidos, en 1930, y a la Argentina, en 1932, periplos que desempeñaron un papel importante en el robustecimiento de las relaciones entre los distintos centros internacionales de la cultura idish y en el interés por el trabajo del Instituto Científico Judío YIVO. Al respecto, resulta oportuno subrayar la importancia del Instituto en la época.

En Polonia YIVO se convirtió en una autoridad en todos los asuntos relacionados con la cultura idish. La asociación con YIVO fue buscada no solo por académicos, sino también por un gran número de personas de todos los ámbitos de la vida, quienes vieron su trabajo para YIVO como un cumplimiento de sus más altas aspiraciones. En las décadas de 1920 y 1930 existían sociedades de amigos de YIVO en Polonia, los países bálticos, Alemania, Francia, Inglaterra, América del Norte y del Sur, Sudáfrica y Palestina. La rama estadounidense se organizó desde $1926 .^{14}$

Imposible resumir aquí toda la labor de Reisen en el terreno a de la cultura y especialmente de la lengua idish. Únicamente a los fines de este trabajo, quise subrayar algunos de sus aportes y sugerir que él fue una de las figuras principales del Instituto Científico de Vilna, tanto por su labor institucional como por sus contribuciones académicas. Estudioso del idioma y la literatura idish, Reisen trabajó como editor, escritor, periodista y activista cultural en Vilna, durante los años de esplendor de dicha urbe que fue uno de los polos de irradiación de la cultura judía en Europa. ${ }^{15}$ En

14 http://yivoarchives.org/index.php?p=pages/yivoarchives_in_vilna.

15 Traverso (2014), p. 44 y Visacovsky (2015). En su análisis sobre la historia del libro judío, Alejandro Dujovne (2012) sostiene que "si comenzamos en el siglo XX, Varsovia y Vilna ocuparían el lugar dominante hasta, al menos, la década de 1920 en la cual emergen algunos centros competidores. Hacia el oeste Berlín adquiere por algunos años un rol importante así como Nueva York sigue su proceso de consolidación como gran centro cultural idish. Hacia el este, y bajo el régimen comunista, Kiev, Odessa y Moscú despliegan por casi dos décadas un lugar de relevancia". Como centros secundarios el autor menciona a Ciudad del Cabo, Cuadernos Judaicos ISSN: 07188749

$\mathrm{N}^{\circ} 36$-Diciembre 2019 178 
efecto, el periodo de actuación de Reisen coincidió con una época dorada de la cultura judía en Europa del Este que, lamentablemente, fue violentamente clausurada con la Segunda Guerra Mundial y la aniquilación de la vida judía en dicho continente. Testigo y víctima de esa época dramática fue Reisen, arrestado tras la ocupación soviética de Vilna en septiembre de 1939, a pesar de la postura radical y pro-soviética que había mantenido el grupo de Vilner en el cual participaba. Su vida culminó en 1941, al ser asesinado por los soviéticos al inicio de la guerra de Alemania y Rusia.

\section{La recepción de la comunidad judía de Tucumán a Reisen}

Fue en el año 1928 cuando se creó en Buenos Aires, Argentina, la sede del Instituto Científico Judío que desde entonces "conserva, investiga y difunde materiales documentales sobre la historia, la cultura y los lenguajes del pueblo Judío". ${ }^{16}$

La Fundación IWO mantiene la biblioteca, el archivo histórico y el museo, creando ámbitos para el estudio, la comunicación inter-generacional y el encuentro entre culturas. Fue creada en el año 1925 en Vilna, el centro cultural de los judíos de Europa Central. En 1928 se estableció su sede en Buenos Aires que comenzó a trabajar en forma independiente a partir de la Segunda Guerra Mundial durante la cual el IWO de Vilna fue sistemáticamente saqueado y destruido. Fundación IWO ofrece una amplia oferta actividades culturales entre ellas cursos de idish y cultura judía, talleres de capacitación en temas de patrimonio cultural, presentaciones de libros y conferencias, conciertos, y mucho más. ${ }^{17}$

La visita de Reisen a Tucumán se sitúa entonces en la época inicial de la vida institucional del IWO ("El nombre IWO se origina en las siglas de Idisher Visnshaftlejer Institut que en idish significa: instituto judío de investigación"). ${ }^{18}$ En efecto, a los pocos años de su establecimiento en la capital argentina, el Instituto recibió a una de las máximas figuras del IWO creado inicialmente en Viena. $\mathrm{Su}$ prestigio como escritor y editor, unido al renombre del mismo Instituto Científico judío, posiblemente explican posiblemente la entusiasta recepción al viajero por parte de la comunidad inmigrante judía en Tucumán. Así El Orden aseguraba que "la llegada del señor Reisen produjo un movimiento inusitado en el ambiente israelita, que desde su llegada le tendió los brazos en una cordial manifestación de simpatía y de reconocimiento". Además, la importancia de esta institución en Buenos Aires es señalada por especialistas como Alejandro Dujovne (2014, p. 73), quien

Montreal, París, y Buenos Aires entre otros y afirma que "la Shoá cambia radicalmente la geografía"; por ejemplo, "como consecuencia de la desaparición del núcleo polaco, Buenos Aires gana un lugar preponderante como productor mundial de libros, aunque no de literatura".

16 http://www.iwo.org.ar/iwo.

17 http://www.iwo.org.ar/iwo.

18http://www.iwo.org.ar/iwo.

Cuadernos Judaicos ISSN: 07188749

$\mathrm{N}^{\circ} 36$-Diciembre 2019 
sostiene que "al instituirse como un polo de investigación y difusión académica de linguiística, historia, sociología y antropología del mundo ashkenazi, este organismo se erigió como la más elevada y renovadora expresión del idishismo".

Por otro lado, no resulta descabellado suponer que los esfuerzos de los dirigentes locales contribuyeron a concretar la misión del delegado del IWO en su tarea de recaudar fondos y apoyos para la organización. En todo caso y como parte de las actividades desarrolladas durante la visita de Reisen, los dirigentes comunitarios organizaron una conferencia en el local de la Sociedad Unión Israelita. En dicha disertación, el sabio judío explicó la obra de estadística, la recopilación de datos históricos, el archivo literario y periodístico, así como "toda la maravillosa acción que realiza y los propósitos que persigue el instituto que representa". Referido a esto último, señaló que

No se conoce a nuestro pueblo y quien lo conoce, lo conoce mal. Se cree que todos somos comunistas o que todos somos buhoneros o sino que todos somos unos Rothschild; nada de nuestra gran obra literaria y científica se conoce; nada de la enorme colonización judía. Uno de los fines del Instituto Científico Judío es dar a conocer al mundo todo esto. ${ }^{19}$

Además, la comunidad judía organizó un lunch en honor a su visita en la Sociedad Unión Israelita. Por otra parte, Reisen dictó una conferencia titulada "Idish y judaísmo" que fue destinada especialmente a la juventud. Esta charla tuvo lugar en las instalaciones de la Sociedad Unión Israelita y fue organizada por el Centro Cultural Sionista Tucumano. ${ }^{20}$

Al respecto, interesa destacar la influencia del idish en las prácticas asociativas de la comunidad judía en la época y el papel que desempeñaron en este aspecto renombrados personajes de la cultura judía europea como Reisen. Pruebas de esta importancia fueron los testimonios contenidos en las fuentes de la comunidad judía tucumana pero también en la prensa periódica local que publicó artículos y fotografías sobre esta visita.

\section{Asociacionismo y mundo cultural judío: una aproximación}

En la época que Reisen visitó Tucumán florecían varias instituciones asociativas judías. Sin ánimo de referirme a la totalidad de las mismas, interesa reconstruir y enumerar algunas de las más significativas. En esa dirección, resulta útil la misma descripción de la comitiva que acompañó al delegado del JIWO en su visita a El Orden. Sabemos que junto con Reisen fueron los representantes de las siguientes asociaciones judías: la Sociedad Unión Israelita, la Sociedad Unión Israelita Residentes de Polonia y el Centro Cultural Sionista Tucumano.

Según la lectura de otras fuentes y apoyada por la bibliografía sobre el tema, es posible afirmar la importancia de la Sociedad Unión Israelita, ámbito que llegó a ser además la principal institución judía local, hasta la actualidad. La historia de esta asociación se remontaba a la década de 1910,

19 El Orden, 17/7/1932.

20 El Orden, 17/7/1932.

Cuadernos Judaicos ISSN: 07188749

$\mathrm{N}^{\circ} 36$-Diciembre 2019 
cuando se creó con el nombre de Sociedad Israelita, con el fin primordial de atender los asuntos religiosos y fundar un cementerio propio. En 1911 la asociación fue renombrada como Sociedad Unión Israelita Tucumana, bajo las consignas de ocuparse de las tareas filantrópicas, culturales, educativas y religiosas (Cohen de Chervonagura, 2010, p. 47).

Por su parte, la Sociedad Unión Israelita Residentes de Polonia se creó en enero de 1926, en consonancia con el crecimiento desde 1921 de la inmigración polaca judía en la provincia. El motivo que llevó a la fundación de esta asociación fue, principalmente, la necesidad de brindar ayuda material a los recién llegados, premisa que excedía las posibilidades de la principal y mayor institución, la ya existente y recientemente nombrada Sociedad Unión Israelita. Otro fundamento que alentó la creación de esta nueva institución fue el interés por auxiliar a los judíos que afrontaban penurias en Polonia (Blumenfeld, 1971, p. 120).

Pocos años después, en 1929, se fundó el Centro Cultural Sionista Tucumano. En efecto, el 9 de julio de ese año, mediante una numerosa asamblea general integrada por hombres y mujeres de la colectividad se creó la nueva asociación, cuyo nombre no fue casual. Según afirmaba Blumenfeld en su estudio, su denominación reflejaba las ideas de sus fundadores, "jóvenes de sólida preparación judía y firmes convicciones acerca del futuro de su pueblo". "Entendieron que la juventud debe sustentar un ideario preciso y una doctrina clara para orientar su vida institucional, sin la cual no sobrevive núcleo humano alguno. Se unieron al sionismo sin embanderarse en ninguna tendencia política, sino porque era la fuente de esperanzas en el resurgimiento nacional del pueblo disperso". ${ }^{21}$

De esta forma, en sus estatutos, el Centro Cultural Sionista Tucumano expresaba como fines: "promover el despertar del sentimiento nacional hebreo en la juventud judía, estrechar vínculos de sociabilidad, fomentar el deporte, fomentar las ciencias y el arte en sus diversas manifestaciones". Como parte de los medios estipulados para alcanzar estos objetivos se encontraban "las conferencias, cursos metódicos de historia, lecturas comentadas, reuniones literarias y musicales, lengua hebrea, literatura judía y actos conmemorativos de fechas nacionales judías”. Además, se estipulaba la necesidad de "sostener la biblioteca popular, editar revistas en castellano --pudiendo usarse el idish o el hebreo--, cooperar en todos los actos de carácter cultural y nacional que realizasen otras instituciones."

Sin ánimo de agotar el tema con estas páginas, es importante subrayar la presencia del sionismo en las actividades asociativas locales y, especialmente, su impacto en la formación comunitaria de los jóvenes judíos. Estrechamente asociado a este ideario nacional del judaísmo, el Centro Cultural Sionista Tucumano marcó el inicio de una época de vitalidad en el asociacionismo judío local, especialmente en el terreno de la juventud. Uno de los episodios más significativos de aquel periodo fue la entrega al Centro Cultural Sionista Tucumano de la Biblioteca "I. L. Peretz". Esta última provenía de los primeros tiempos institucionales de Sociedad Unión Israelita, ya que se había organizado en 1914 como Biblioteca Popular y al año siguiente, en 1915, cambió su denominación para llamarse desde entonces "I. L. Peretz", como un homenaje al célebre escritor judío que había fallecido en Polonia ese año. El grueso de los ejemplares que contenía dicha biblioteca era de

21 El Orden, 19/09/1928. 
literatura en idish y entre este material y la literatura en castellano reunía unos 1500 ejemplares (Blumenfeld, 1971, pp. 60-61).

Fueron numerosas las actividades de naturaleza social y cultural motorizadas por la Biblioteca "I. L. Peretz". Eventos literarios, conferencias, funciones de teatro y veladas culturales de preguntas y respuestas atraían a un vasto público que se daba cita en la sala de lectura de la Biblioteca. En especial los jóvenes eran quienes más asistían a estas veladas culturales, donde leían, discutían y ensayaban representaciones del teatro judío clásico. Asimismo, la Biblioteca auspició la creación de nuevos emprendimientos asociativos. Tal fue el caso de la fundación en setiembre de 1928 del Conservatorio Israelita "Mendelssohn", organismo que se constituyó con el apoyo de la Biblioteca, del Centro Juventud Israelita Pro-Cultura y Fondo Nacional. Dicho conservatorio sería dirigido por el conocido violinista Adolfo Valenti. Al respecto, la prensa publicó una noticia en donde entrevistaba al músico.

Un detenido y consciente estudio de la situación en que la colectividad israelita argentina se ha colocado, por su crecido número y por sus cualidades, han inducido a pensar en la necesidad de que haya una institución de esta índole que abarque todas las ramas de acción posibles de cultivar en un grupo numeroso y culto de personas. No admitimos como suficientes las agrupaciones sociales ya existentes, sin por eso desmerecer sus altos valores los cuales reconocemos y justiprecian, como así tampoco la limitación desacertada de sus funciones. Un vasto plan de acción se ha trazado el director en bien de la novel institución, que iniciará sus audiciones el 29 del corriente con una audición interesante para la cual se ha preparado un selecto programa. ${ }^{22}$

El Centro Juventud Israelita Pro-Cultura y Fondo Nacional se había fundado en junio de 1925 e integraba a jóvenes de origen europeo con los nacidos en Tucumán. Esta asociación se había conformado bajo los influjos de la visita a la provincia del reconocido político e intelectual sionista, el Dr. Bensión Mossensohn. Bajo este ideal agrupaba a la juventud que hablaba idish junto con aquellos que por haber nacido en estas tierras empleaban el castellano; durante los cuatro años de su existencia trabajó a favor de los intereses del Fondo Nacional Judío (Blumenfeld, 1971, p. 117).

El tejido asociativo judío se expandió entre mediados y finales de la década del '20. Una muestra en ese sentido fue la obtención de la personería jurídica a comienzos de 1925 de la Asociación Chevrah Keducha Ashkenazi Tucumana que canalizó sus esfuerzos en obtener "el permiso municipal para habilitar el terreno de propiedad institucional como cementerio israelita". Más adelante, a finales de 1929 se estableció el Club Atlético Israelita con el fin de atraer a los jóvenes judíos a la vida comunitaria. Para ello, la asociación encabezaba actividades deportivas y sociales y posteriormente sumaron eventos culturales.

Un análisis de las fuentes permite plantear que en los primeros años de la década de 1930 comenzó un periodo pleno de actividades culturales. Por ejemplo, la Sociedad de Residentes de Polonia 
propició la actividad teatral desde 1930, y su Biblioteca Libre y sus reuniones literarias evidenciaron el esplendor de sus labores. Por su parte, el Centro Cultural Sionista Tucumano impulsó representaciones teatrales en idish. Los grupos artísticos locales pusieron en escena numerosas obras del repertorio judío, como "Der Talmid" (El Erudito) y "Undzere Kinder" (Nuestros hijos), entre muchas otras piezas del teatro idish. Además, sobresalieron las actuaciones de artistas como Berta Singerman, cuya presentación de 1931, especialmente, la recitación de la poesía "Después del entierro" de I.L- Peretz, fue destacada por la colectividad judía (Blumenfeld, 1971, p. 168).

Berta Singerman (1901-1998) fue una recitadora nacida en Minsk (Rusia) que huyendo del zarismo ruso y los pogroms inmigró con su familia a la Argentina cuando era una niña pequeña. ${ }^{23} \mathrm{Su}$ trayectoria reconoció las huellas de la cultura judía expresada a través del teatro y la poesía idish que le transmitía su padre. Animada por esta influencia, ella actuó en obras de teatro en idish cuando era una niña de 8 años y participó en giras por el interior del país. Al igual que otras mujeres artistas judías, Singerman transitó del idish al castellano, tal como sostiene Sandra McGee Deutsch, ${ }^{24}$ y fue en el terreno de la declamación poética en el cual alcanzó fama nacional e internacional, al triunfar en escenarios de EEUU, Latinoamérica, Brasil, España y Portugal. ${ }^{25}$

Una lectura de la prensa local permitió completar la información que teníamos hasta el momento sobre las presentaciones de Singerman en Tucumán. Por ejemplo, a partir de los artículos publicados en 1928 por El Orden sabemos que ella estuvo ese año en la provincia, donde --según esta fuente-- ofreció exitosas presentaciones y recibió una excelente respuesta por parte del público. $^{26}$ Con grandes elogios y definiciones positivas, tales como "eminente intérprete", "admirable recitadora" y "magnífica creadora del arte de la declamación en nuestro país", el diario difundió numerosos artículos en los cuales narraba detalladamente cada una de estas presentaciones. ${ }^{27}$ A través de estos relatos, sabemos que Rubén Darío, Gabriel D' Annunzio, Alfonsina Storni y Juana Inés de la Cruz fueron algunos de los y las poetas recitados por la artista en las cuatro funciones que brindó a sala llena en uno de los principales teatros de la ciudad: el Teatro Alberdi. ${ }^{28}$

23 Más información en Singerman, 1981.

24 Esta idea la tomé de McGee Deutsch (2017, pp. 146-147), quien señala, además, como, al igual que en Estados Unidos, "las mujeres asquenazíes comenzaron en el teatro idish. Las obras en idish comenzaron a representarse en Buenos Aires en 1901, y treinta años después la ciudad era uno de los cuatro centros más importantes de teatro idish del mundo".

25 Singerman recitó a los grandes poetas de lengua castellana: Lope de Vega, Rubén Darío, Antonio Machado, Federico García Lorca y Gabriela Mistral; fundó y dirigió la Compañía de Teatro de Cámara en 1932 y para el año 1945 contaba ya con su propia compañía estatal. Su representación de "La voz humana", de Jean Cocteau, llegó a ser considerada la mejor del mundo y a lo largo de su carrera recibió numerosos premios y reconocimientos. Pérez Adán (2018) y Escobedo Cubells (2005).

26 El Orden, 11/09/1928 y 12/09/1928.

27 El Orden, 11/09/1928 y 12/09/1928.

28 El Orden, 14/09/1928. 
Más adelante, en 1931, y en un contexto de gran expectativa por su visita, Singerman volvió a la provincia, ${ }^{29}$ aunque esta vez fue como intérprete teatral. ${ }^{30}$

Conocíamos a Berta Singerman recitadora, a esa Berta que con su voz vibrante, su gesto que parece querer hablar, más de una vez supo llenar el alma y anudar las gargantas de emoción, hasta arrancar la ovación cerrada y espontánea, de las muchedumbres que al sólo conjuro de su nombre llenaban las salas de espectáculos donde actuaba. Anoche conocimos a la otra Singerman, a la actriz. Dudábamos, afortunadamente sin motivo, pensábamos que su primitivo arte llegaría a dominarla. Pero no, ágil, sugestiva, de hablar claro y conciso, de ademán medido, salvo uno que otro pasaje, donde por instantes, hizo gala de una ampulosidad desmedida, sin llegar empero a desmerecer el mérito de su interpretación; ella se nos reveló como antes: Única. ${ }^{31}$

Su vasto y rico repertorio se nutría tanto de la cultura judía como de obras universales, tal como se relejó, por ejemplo, en las numerosas piezas teatrales que representó ese año en Tucumán, entre las cuales se incluyeron "Almuerzo de enamorados", del escritor francés Birabeau, "El doctor Doath de 3 a 5", de Azorín, "La señorita Julia", del gran dramaturgo nórdico August Strindberg, "Ana Karenina", de Tolstoi y "Después del entierro", escrito por unos de los principales escritores judíos de la época, Isaac León Peretz, considerada como una obra prima del teatro de cámara y "una pieza que por su intensidad y por su gran valor literario es valorada como una obra maestra". 34

\section{A modo de conclusión}

En este trabajo analicé algunas actividades de asociación y cultura motorizadas por la comunidad judía ashkenazi en Tucumán entre finales de los años 1920 y comienzos del '30. En esa dirección, examiné la visita de Zalmen Reisen, quien llegó a la provincia como parte de una misión dirigida a recaudar fondos y respaldos para el Instituto Científico Judío de Vilna que --como ya se dijo en el trabajo-- contaba con una sede en Buenos Aires. Examinar la estancia del sabio judío en Tucumán

29 El Orden, 18/02/1931, El Orden, 26/02/1931 y El Orden, 28/06/1931.

30 El Orden, 14/07/1931 y El Orden, 17/07/1931.

31 El Orden, 17/07/1931.

32 El Orden, 25/07/1931.

33 El Orden, 26/07/1931.

34 El Orden, 27/07/1931 y 31/07/1931. El Orden, 23/07/1931. "El maleficio de la luna”, de Massimo Bontempelli y "La invitación al viaje", de Jean Jacques Bernard, fueron otras de las obras que presentó Singerman en Tucumán. Interesa agregar que varias de estas funciones culminaron con una audición poética por parte de la artista. 
fue el punto de partida para reconstruir el tejido asociativo judío local e indagar algunas de las principales actividades culturales puestas en marcha en el periodo.

Del examen realizado, se desprenden las siguientes conclusiones:

La primera, se refiere a la importancia de la Sociedad Unión Israelita, institución madre del asociacionismo judío tucumano, a partir de la cual surgieron numerosos emprendimientos que dependieron de esta institución o bien, transitaron caminos independientes.

Otra consideración alude a la importancia del sector judío procedente de Polonia, en consonancia con las características de la inmigración judía en el resto del país en donde este grupo ocupó un lugar preponderante. ${ }^{35}$

En tercer lugar, quisiera proponer la influencia que alcanzaron los sentimientos nacionales, entendidos en términos de sionismo, en el asociacionismo judío en Tucumán. El sostenimiento de esta ideología requería desestimar las tendencias políticas, al entender que éstas podían originar tensiones y fracturas al interior de la comunidad judía. También, suponía buscar y fomentar un conjunto de herramientas dirigidas a promover la identidad judía y los principios sionistas, especialmente entre los jóvenes de la comunidad.

Por otro lado, interesa sugerir la centralidad que alcanzó el terreno de la cultura y, en especial, la cultura idish, en la vida asociativa judía. Esto se reflejó, por ejemplo, en la conformación y el desarrollo de instituciones que otorgaron un valor central a la organización de veladas literarias, concursos de preguntas y respuestas, representación de obras teatrales, dictado de conferencias, recitales poéticos y creación y sostenimiento de bibliotecas que reunían material escrito en idish y en castellano. A través de este conjunto de actividades que incluían disertaciones, lecturas y teatro, entre otras expresiones, los integrantes de la comunidad judía de Tucumán recuperaban y recurrían a escritores, intelectuales, autores y dramaturgos tanto de la cultura universal como del repertorio judío, en el cual el idish tenía un lugar nodal.

En ese ambiente cultural, podemos inscribir las actuaciones de Berta Singerman en Tucumán, quien al transitar del idish al castellano, como ya se dijo en el trabajo, evoca el pasaje de la tradición proveniente de Europa oriental a las nuevas prácticas y costumbres adquiridas tras la inmigración en el país.

Por su parte, Reisen, quien puede ser descrito como uno de los principales exponentes de la cultura judía de Europa oriental, testimonia con su accionar un ambiente judío floreciente donde el idish ocupaba un lugar medular. En especial, por su carácter de delegado del YIVO y su papel como intelectual y difusor de la lengua y la literatura idish, ocupó un lugar renombrado en la ciudad de Vilna, caracterizada por el dinamismo y la riqueza de su vida cultural.

35 La importancia de la inmigración ashkenazi es señalada, por ejemplo, en Dujovne, 2014, pp., 17-20 y 6667 y Visacovsky, 2015, pp. 34-35. Sobre la influencia de la inmigración polaca judía, Bargman, 2011, en especial pp. 165-168. 
Pero si la trayectoria de Reisen testimonia la centralidad del mundo del idish en el seno de una fértil cultura judía en los años de entreguerras, su recorrido biográfico evoca también el dramático derrotero de los judíos europeos asesinados durante la Segunda Guerra Mundial. En el contexto de la ocupación soviética a Vilna, el YIVO fue destruido, así como el resto de las manifestaciones culturales, científicas, artísticas y religiosas judías. La vitalidad del espectro cultural judío y el ámbito del idish que habían florecido a través de libros, revistas, periódicos, asociaciones e instituciones fueron arrasadas por el conflicto bélico y el terror nazi. ${ }^{36}$

Con lo cual y en contraste con épocas anteriores a la guerra, donde una numerosa población judía vivía y laboraba en diversas latitudes europeas, resulta sumamente estremecedor observar en la actualidad como en dichas geografías las presencias fueron sustituidas por monumentos y placas conmemorativas. Estrechamente relacionado con lo anterior, el universo del idish y del judaísmo pasó al terreno de la memoria y del pasado.

Reconstruir las historias y los aportes vinculados con esta vida cultural judía destruida en Europa fue uno de los objetivos que animaron estas páginas. En particular, el trabajo busca contribuir a la recuperación de estas historias íntimamente conectadas con el idish en Argentina, uno de los países con mayor inmigración judía. Más particularmente aún, el trabajo aspira a ser un aporte para el examen de esta problemática en Tucumán, espacio provincial que carece de este tipo de aproximaciones históricas y en donde habita una de las mayores comunidades judías del país.

\section{Bibliografía}

Bargman, D. (2011). "Judíos oriundos de Polonia en la Argentina: construcciones identitarias y asociacionismo étnico hasta la segunda postguerra", en E. Kahan, L. Schenquer, D. Setton y A. Dujovne (compiladores), Marginados y consagrados. Nuevos estudios sobre la vida judía en Argentina (pp. 165-190). Buenos Aires. Lumiere.

Blumenfeld, I. (1971). Historia de la comunidad Israelita de Tucumán. Tucumán, Editado por la Sociedad Unión Israelita Tucumana.,

Chinski, M. (2011). "Un catálogo en memoria del judaísmo polaco. La colección Dos polyche yidntum, Buenos Aires, 1946-1966", en E. Kahan, L. Schenquer, D. Setton y A. Dujovne (compiladores). Marginados y consagrados. Nuevos estudios sobre la vida judía en Argentina (pp. 213-238). Buenos Aires. Lumiere.

36 Sobre las consecuencias que tuvo la destrucción del centro polaco para la producción y edición en idish de Buenos Aires, Dujovne (2014, pp. 284-285) sostiene que con el fin de la Segunda Guerra Mundial, "Buenos Aires vivió un proceso de expansión de la edición tanto en idish como en castellano". De este modo, "a partir de la Segunda Guerra Mundial y al menos por un par de décadas Buenos Aires experimentó un notable despegue editorial que posibilitó comenzara a proveer de libros en lengua idish al conjunto de la diáspora", Dujovne, 2012. 
Cohen de Chervonagura, E. (2010). La comunidad judía de Tucumán. Hombres y mujeres, historias y discursos, 1910-2010. Tucumán, Sociedad Unión Israelita Tucumana, Kehilá.

Cohen de Chervonagura, E. (2015). Eshet Jail, Un contrapunto entre dos mujeres judías. Tucumán, Universidad Nacional de Tucumán.

Dujovne, A. (2014). Una historia del libro judío. La cultura judía a través de sus editores, libreros, traductores, imprentas y bibliotecas. Buenos Aires, Siglo XXI.

Dujovne, A. (2012). "Buenos Aires en la geografía de la diáspora judía. Una aproximación desde la producción y circulación transnacional de libros entre 1900 y 1980". http://estudiosjudios.ides.org.ar/files/2012/02/bibliotecas_Buenos_Aires_en_la_geografia_de_la_di aspora_judia.pdf.

Escobedo Cubells, P. (2005). "Manusrits I Arxius Personals. Archivo personal de Berta Singerman", Revista de la Biblioteca Valenciana, 8.

Gleizer, D. y Kahan, E. (2017). "Los estudios judíos desde Latinoamérica: temas, perspectivas y diálogos con otras agendas académicas", Cuadernos Judaicos, 34, 1-6.

Kahan, E. y Dujovne, A. (2017). "Los estudios judíos en Argentina y su legitimación en el campo académico: balance y perspectivas", Cuadernos Judaicos, 34, 7-32.

León, D. (2002). La vela encendida. Cinco relatos de mujeres que hicieron el Shabat. Tucumán, Instituto Interdisciplinario de Estudios Latinoamericanos, Facultad de Filosofía y Letras, Universidad Nacional de Tucumán.

Pérez Adán, L. M (2018). "Cartagena. Berta Singerman, mucho más que una recitadora". http://www.laverdad.es/murcia/cartagena/berta-singerman-recitadora-20180505012901-nt.html

Silberman de Cywiner, M. E. (2006). Asociación Israelita Sefaradí de Beneficencia de Tucumán. Memoria y testimonios de su fundación y evolución. Tucumán, Instituto de Literatura Española (ILE), Facultad Filosofía y Letras, Universidad Nacional de Tucumán, 2006.

McGee Deutch, S. (2017). Cruzar fronteras, reclamar una nación. Historia de las mujeres judías argentinas, 1880-1955. Buenos Aires, Fondo de Cultura Económica.

Novershtern, A. (2010, November 18). Reyzen, Zalmen. YIVO Encyclopedia of Jews in Eastern $\begin{array}{lllll}\text { Europe. } & \text { Retrieved } & \text { March } & 1, & \text { 2019, }\end{array}$ http://www.yivoencyclopedia.org/article.aspx/Reyzen_Zalmen.

Silberman de Cywiner, M. E. (2012), (compiladora). El patrimonio olvidado, Identidad y memoria, Tucumán, Universidad Nacional de Tucumán. 
Singerman, B. (1981). Mis dos vidas. Buenos Aires, Ediciones Tres Tiempos, 1981.

Traverso, E. (2014). El final de la modernidad judía. Historia de un giro conservador (Buenos Aires, Fondo de Cultura Económica.

Visacovsky, N. (2015). Argentinos, judíos y camaradas. Tras la utopía socialista. Buenos Aires, Editorial Biblos, Colección La Argentina Plural. 